\title{
MONITORING SEISMIC DISPLACEMENTS USING GNSS DATA WITH PPP METHOD
}

\author{
Pikridas C. ${ }^{1}$, Bitharis S. ${ }^{1}$, Fotiou A. ${ }^{1}$, Rossikopoulos D. ${ }^{1}$, Katsougiannopoulos \\ S. ${ }^{1}$, Spanakaki K. ${ }^{1}$ and Karolos I. ${ }^{1}$
}

${ }^{1}$ Aristotle University of Thessaloniki, Department of Geodesy and Surveying, 54124, Thessaloniki, Greece,cpik@topo.auth.gr, stylbith@gmail.com,afotiou@topo.auth.gr,rossi@topo.auth.gr

\begin{abstract}
The Precise Point Positioning (PPP) analysis method adapted for monitoring coordinate displacements from GNSS permanent stations data. One week period data were analyzed covering the Samothrace strong earthquake event of 6.8M. The sample data were processed with Bernese v5.2 PPP engine and with the online web platform of JPL which uses the GIPSY/OASIS v6.3 software package. Also, for validation purposes the output results were compared with those derived by network analysis by means of the GAMIT processing software of MIT. Our experiments proved the ability to measure dynamic seismic related coordinate variations at sub-centimeter level using the PPP algorithm. But this is efficient when strong earthquakes occurs and for stations close to epicenter.
\end{abstract}

Keywords: GNSS data, precise point positioning, earthquake, site displacements.

\section{Пєрí̇}

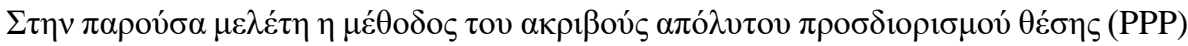

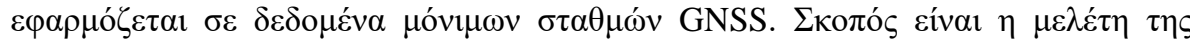

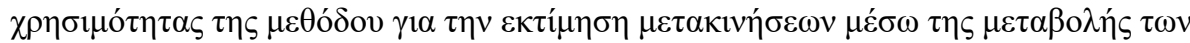

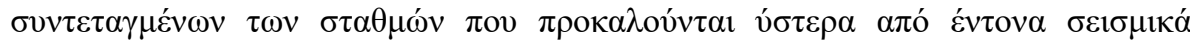

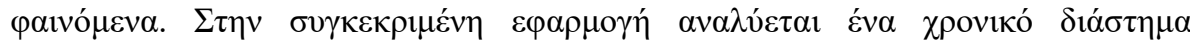

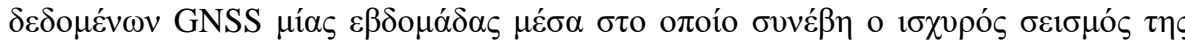

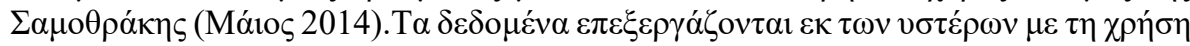

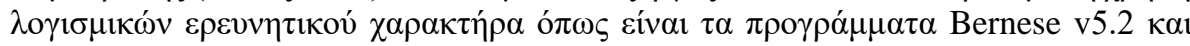

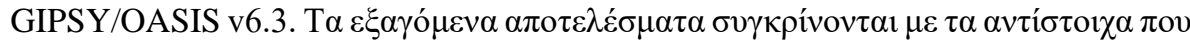

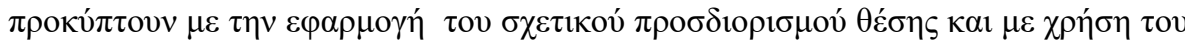

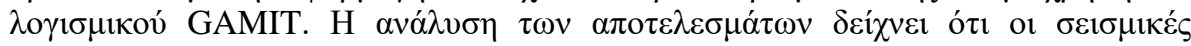

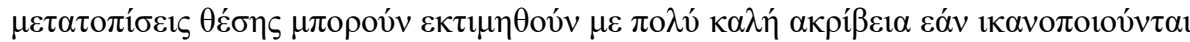

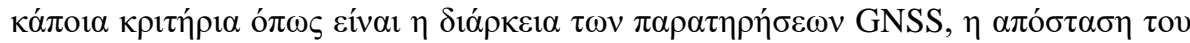

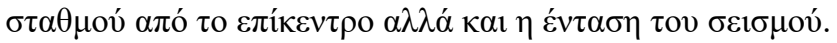

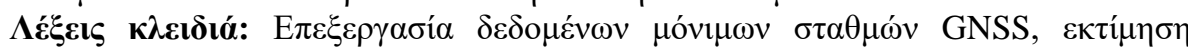

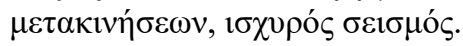

\section{Introduction}

In recent years GNSS (Global Navigation Satellite Systems) have attracted increased attention and numerous applications in seismic events and in general in hazard monitoring. Data analysis, especially on high rates like $1 \mathrm{sec}$, proved the ability to detect seismic waves related to strong earthquakes. Compared with conventional geodetic techniques, GNSS techniques generally increase 
survey accuracy, productivity, and monitoring capability. Consequently, dense GNSS monitoring networks have been established in many countries and also on seismically active regions like Greece. For this reason, precise GNSS data analysis and especially in real time mode is crucial for monitoring purposes. The well-known method of relative positioning is the predominantly used for high accuracy results. But this method has time computational limitations due to differencing simultaneous data from tens or hundreds of ground stations. Alternatively, precise point positioning (PPP) method can provide displacements with respect to a global reference frame (defined by satellite orbits and clocks) using data from only one GNSS receiver. PPP is more flexible because it is a typical absolute positioning method using un-differenced dual-frequency pseudo-range and carrier-phase observations along with precise satellite orbit and clock information to determine the position of a stand-alone GNSS station (e.g., Zumberge et al., 1997; Kouba et al., 2001). Another advantage of PPP is that since the GNSS orbit and clock products are global, the PPP solutions are global as well. The PPP algorithm has been included into several scientific GNSS processing softwares like Bernese and GIPSY/OASIS. PPP could offer a good opportunity to conduct accurate displacements during and after seismic events. In this study the implementation of PPP using the Bernese software v5.2 and the processing platform provided through the Jet Propulsion Laboratory (JPL) web page was tested. This platform uses the GIPSY software v6.3 and can directly estimate receiver position. Daily data from ten GNSS stations of SmartNet (www.metricanet.gr), Hepos (www.hepos.gr) and Hermes (Fotiou et al., 2010) permanent Networks were used for a one week period. As a consequence, the potential and limits of the PPP method are tested on a strong earthquake which occurred, within the testing period, between the islands Lemnos and Samothrace at the northern region of Greece. The derived results were also compared with those estimated from network solution processing using GAMIT software of MIT for further validation (Herring et al., 2010). In general, PPP process provides slightly less accurate than relative positioning results. But it can register the seismic displacements when a strong earthquake shock occurs and this scenario can be operational in (near) real time mode.

\section{Estimation of Samothrace earthquake related displacements}

\subsection{The seismic event}

A strong earthquake struck off the coast of northern Greece on Saturday 24th May, at 09:25 (UTC) and was felt as far away as neighboring Turkey and Bulgaria with no reports of serious casualties or destruction. The quake occurred about $77 \mathrm{~km}$ (48 miles) south-southwest of Alexandroupolis, between the islands of Lemnos and Samothrace, at a depth of $12 \mathrm{~km}$ (7 miles) (Sboras et al., 2015). The magnitude varies from MW6.2 (AUTh) up to MW6.9, as suggested by the majority of institutes. Figure 1 displays the main shock and aftershocks occurred within the day (24th May) as provided by relevant webpage of the Department of Geophysics of AUTh (http://geophysics.geo.auth.gr).

\subsection{The applied PPP method for seismic displacements estimation}

Precise Point Positioning (PPP) is a relatively new high precision method of positioning providing few centimetres-level error. PPP processes dual-frequency pseudorange and carrier-phase measurements from a single (user) receiver, using detailed physical models and precise GNSS orbit and clock products calculated beforehand. PPP can be applied at post-processing level and also in real-time provided that real-time input orbit and clock data are available. The accurate performance of the PPP is considered to be an excellent starting point for starting the analysis of the PPP technique for various geodetic applications, such as the detection and localization of seismic ground motion. 


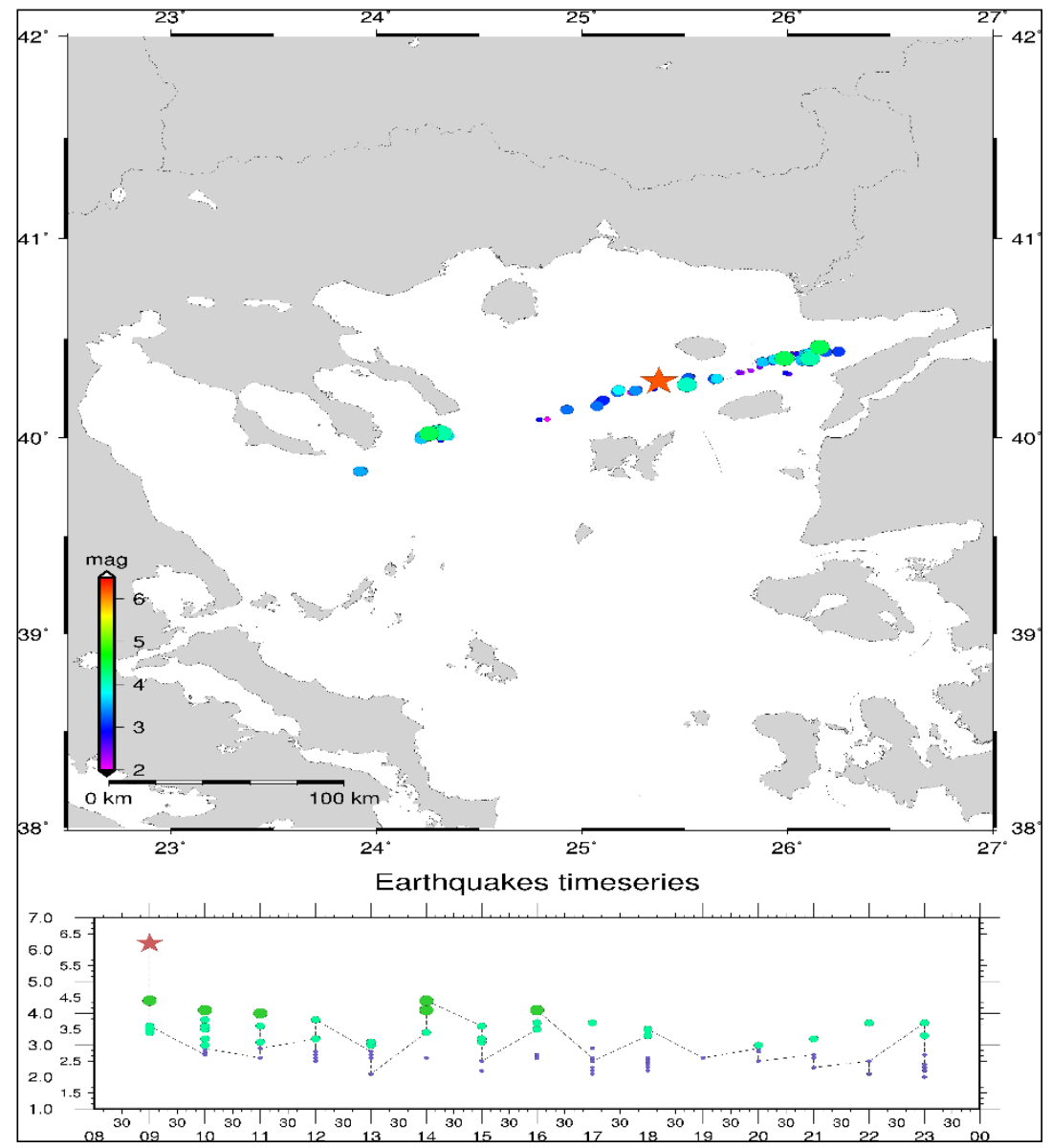

Figure 1 - Earthquake activity in 24 May 2014 between islands Lemnos and Samothrace NE of Greece.

It's positioning accuracy depending on the number and geometry of visible GPS satellites, and the quality of observations. For a data files spanning 24 hours the positioning accuracy can be less than $5 \mathrm{~cm}$ (Fotiou and Pikridas, 2012). This is performed in the present study because daily station data were processed for a period of seven days starting from 20 until 26 of May 2014. It is worth to be mentioned that most of the permanent stations records at a $30 \mathrm{sec}$ rate GPS and Glonass data which is an advantage for the impact of Satellite geometry in the process. In this study two processing PPP scenarios were implemented. First, the Bernese v5.2 GNSS software was used. Referring to the basic information for data processing parameters, the dedicated BPE process control file (pcf) for estimating station coordinates was selected (Dach et al., 2015). This includes that the GNSS data were analyzed with a satellite elevation cut-off angle of 10 degrees, final precise orbit information was used from IGS directory (available after 12 days) which refers to the IGb08 reference frame and the new IGS_08.atx model with absolute antenna calibration values was applied. For the tropospheric refraction, the Saastamoinen model (Saastamoinen, 1972) with VMF mapping function was used (Boehm et al., 2006). In addition, the Differential Code Biases (DCB) file for all satellites was retrieved from the AIUB Data Center of the University of Bern. Therefore, the every $5 \mathrm{~min}$ position series were derived for all stations. At the second scenario we reprocessed the GNSS data only for the day of Earthquake (24th May) by means of the automatic PPP technique provided through the Jet Propulsion Laboratory (JPL) web page (http://apps.gdGPS.net/). This platform uses the GIPSY software v. 6.3 and can directly estimate receiver position along with other parameters by introducing IGS precise satellite orbit and satellite clock information (Zumberge et al., 1997). 
All of the derived stations cartesian coordinates were transformed to topocentric according to NorthSouth and East-West direction. Figure 2 shows the geographical distribution of the analyzed permanent stations (red bullets) and the epicentre of the main shock (red star). Closest to epicentre is 018B GNSS station which located on the island of Samothrace and only $16 \mathrm{Km}$ away.

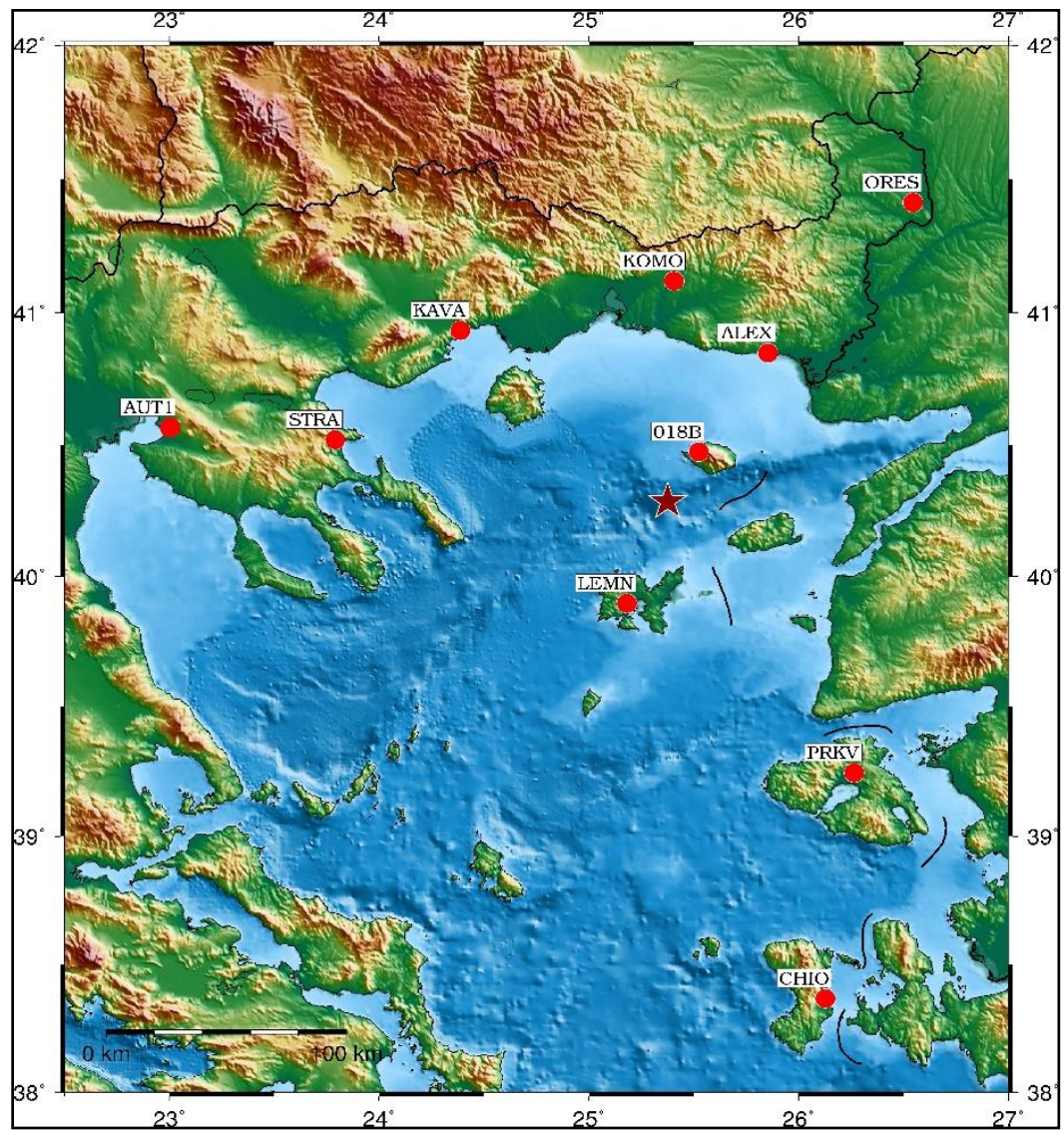

Figure 2 - The analyzed permanent GNSS stations in the period of the Samothrace earthquake.

In order to evaluate the overall precision of PPP and consequently the site displacements, the daily solutions and not the epoch kinematic of every 5 minutes, were compared with those derived from network adjustment using the GAMIT software (Sboras et al., 2015; Bitharis et al., 2016). Coordinate comparisons of 018B station (epicentre) are illustrated in figures $3 \mathrm{a}$ and $3 \mathrm{~b}$ for North, East and Up component respectively. These figures show the differences of each daily solution for both processes (PPP and GAMIT) from the first day solution and for the test period. The final results from GAMIT analysis show $3.5 \mathrm{~cm}$ and $8.7 \mathrm{~cm}$ for the N-S and E-W direction respectively. As it is clearly shown PPP solutions registered the earthquake motions on the same components. But the displacement magnitude is less accurate for only few millimetres. We would like to note again that these PPP results are too accurate because we processed daily data. 

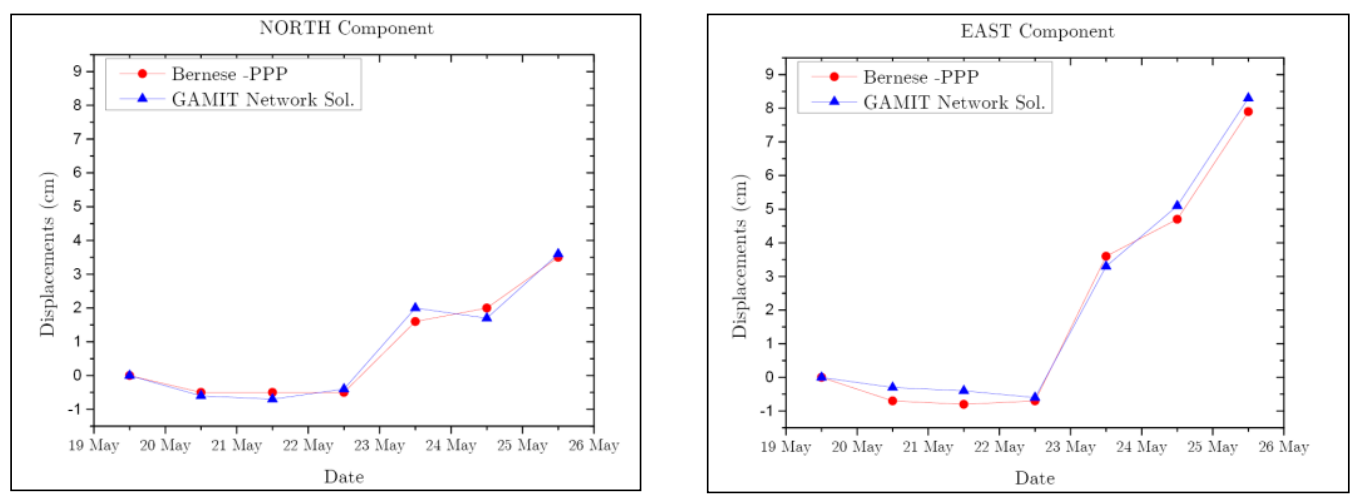

Figure 3a - North and East displacements of daily PPP and GAMIT solutions for station 018B.

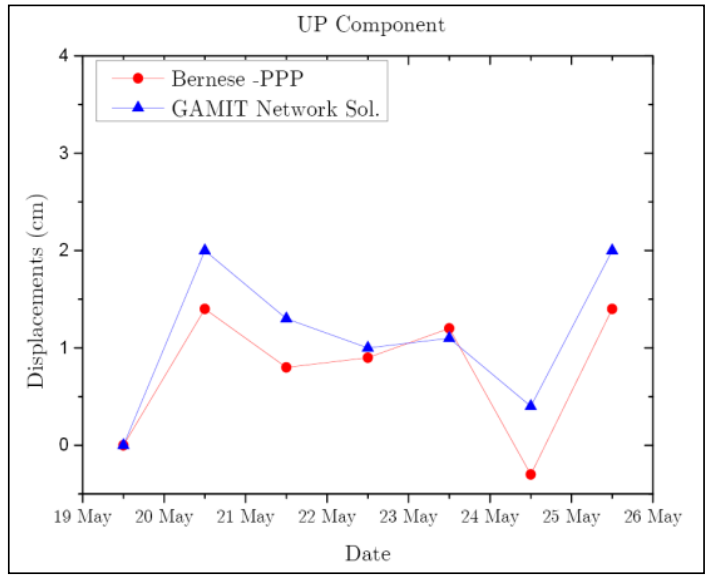

Figure 3b - Up displacements from daily PPP and GAMIT solutions for station 018B.

Subsequently comparisons between Bernese and the global platform of automated PPP using GIPSY-OASIS for 018B station were performed. Those refer to each position estimations (every 5 $\min )$ for the day of earthquake ( $24^{\text {th }}$ of May). Figure 4 shows the position variation for all components (N, E, Up) from the start epoch solution of the used software packages. The green vertical line indicates the occurrence of earthquake in GPS time. Some large differences epoch solutions that occur (for the case of Bernese) are due to the step of ambiguities estimation. This unstable behaviour could be larger for real time PPP use as the sparse global reference network employed cannot provide accurate delays for fast ambiguity estimation. In addition, if the stations records in higher observation rate than the $30 \mathrm{sec}$ (e.g. $1 \mathrm{sec}$.) we could be able to get more detailed signature of seismic duration.

One more test performed in this study was the determination of the post seismic drift-displacement according to the distance from the epicentre of the permanent station. Therefore, the time series of the nearest three stations 018B, LEMN and ALEX located at 16, 60 and $70 \mathrm{~km}$ away respectively were examined. Figure 5 illustrates the "kinematic" PPP positions variations of every 5 minutes for the three stations on North, East and Up component. It is clear that, for 018B station the significant seismic drift is well estimated. For the station at Lemnos island the sensitivity is remain but the variation is growing. 

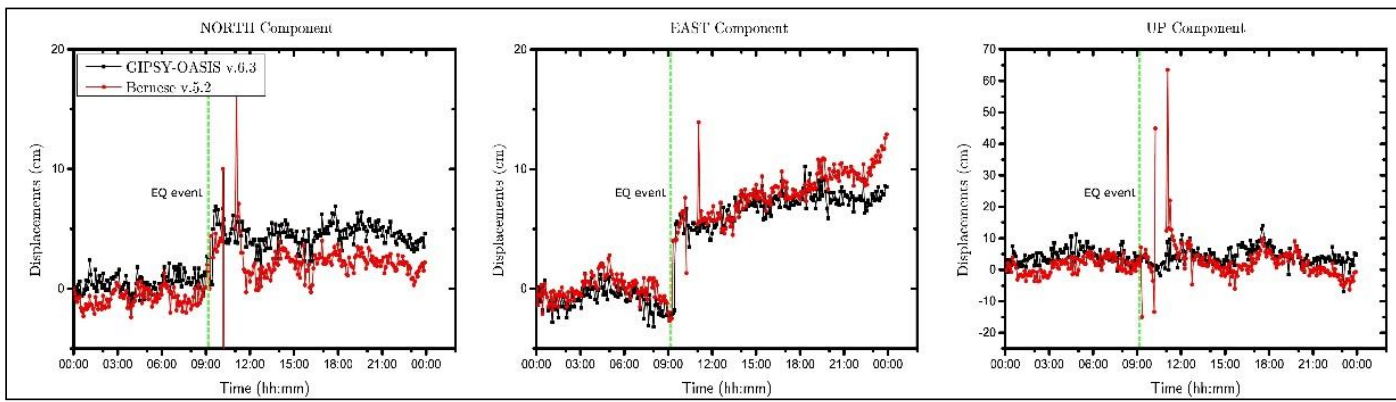

Figure 4 - Horizontal and vertical position displacements of epicentre GPS station in the day of seismic event.

More specific, the variation on North component was from -2 to $-7.6 \mathrm{~cm}$. The "true" value was equal to $4.7 \mathrm{~cm}$ (derived from GAMIT). As it concerns the ALEX station (located at the city of Alexandroupolis) the displacement sensitivity is even less and with bigger uncertainty. "True" estimation was equal to $1.8 \mathrm{~cm}$ and $1.2 \mathrm{~cm}$ for North and East respectively. Therefore, the displacement can't easily be distinguished from the positional accuracy. As it concerns the real time operation mode, the results could be quite different due to corrections and mainly due to position variation during the shock and as consequence the capability in ambiguity estimation step. In this case, an adaptive position filter maybe needed especially for GNSS stations on longer distances from the epicentre.

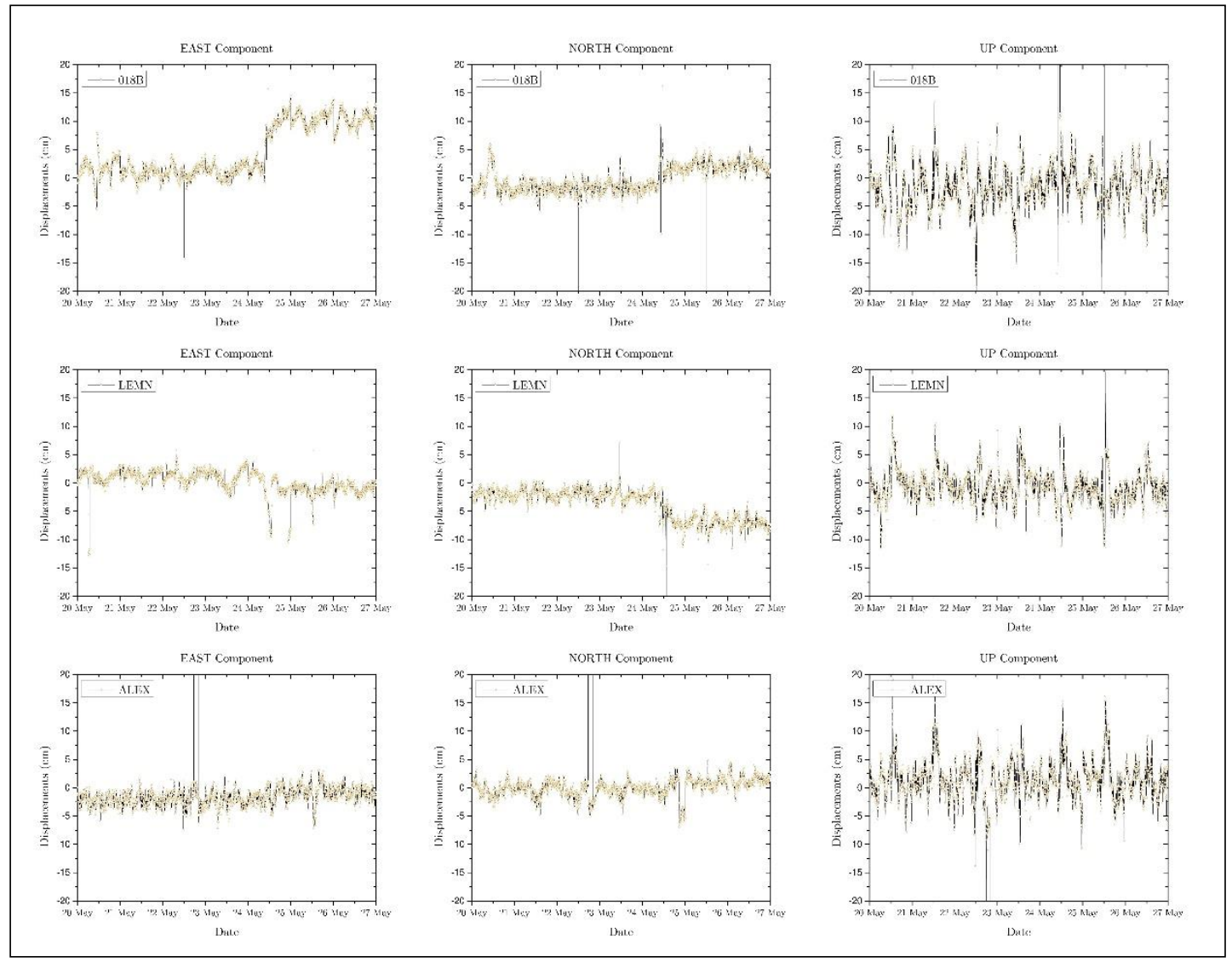

Figure 5 - Time series of PPP position displacements of three nearest permanent GNSS stations to the earthquake epicentre for the test period. 


\section{Conclusions}

The paper aims to assess the feasibility of PPP method for monitoring catastrophic events, such as earthquakes. Having quick information about the ground movement during the earthquake in the vicinity of the fault is vital in order to foresee the consequences and generate timely alerts if necessary. The estimated displacements were compared with those derived by network solution process and found that PPP, using daily data files, can register the strong earthquake shock with an accuracy of several millimetres. At pseudo kinematic operation mode, PPP outputs are less accurate especially for permanent stations away from the earthquake epicentre.

In general, PPP can help the early detection of seismic events, and thus contribute to the mitigation of the potential subsequent disaster consequences.

\section{Acknowledgments}

The authors would like to thank Metrica S.A (Leica-SmartNet/Greece) and National Cadastre and Mapping Agency S.A (HEPOS) for providing GNSS data.

\section{References}

Bitharis, S., Fotiou, A., Pikridas, C, Rossikopoulos, D, Pavlides, S. and Chatzipetros, A., 2016. The Samothrace earthquake of may 2014 and the displacements estimations using permanent GPS stations data, Bull. Geol. Soc. Greece, L.

Böhm, J., Werl, B. and Schuh, H., 2006. Troposphere mapping functions for GPS and very long baseline interferometry from European Centre for Medium-Range Weather Forecasts operational analysis data, J. Geophys. Res., 111, B02406, doi: 10.1029/2005JB003629.

Dach, R. and Walser, P. 2015.Tutorial of Bernese GNSS software version 5.2. AIUB, Bern, Switzerland.

Fotiou, A., Pikridas, C., Rossikopoulos, D., Spatalas, S., Tsioukas, V. and Katsougiannopoulos, S., 2010. The Hermes GNSS NtripCaster of AUTh, Bulletin of Geodesy and Geophysics, LXIX/1.

Fotiou, A. and Pikridas, C., 2012. GPS and Geodetic Applications, 2nd edition Ziti Publications, $490 \mathrm{pp}$.

Herring, T.A., King, R.W. and McClusky, S.C., 2010. GAMIT Reference Manual: GPS Analysis at MIT. Department of Earth Atmospheric and Planetary Science, Massachusetts Institute of Technology. Cambridge, USA.

Kouba, J. and Héroux, P., 2001. Precise Point Positioning Using IGS orbits and Clocks Products, GPS Solutions, 5(2), 12-28.

Saastamoinen, J., 1972. Atmospheric correction for the troposphere and stratosphere in radio ranging of satellites, in The Use of Artificial Satellites for Geodesy. In: Geophys. Monogr. Series, 15, Henriksen S.W, Mancini, A. and Chovitz, B.H., eds., 247-251, AGU, Washington D.C.

Sboras, S., Chatzipetros, C., Pavlides, P., Pikridas, C., Fotiou, A. and Bitharis, S., 2015. The May 24, 2014 North Aegean Trough earthquake: stress change and displacement patterns, Proc. of the 6th International INQUA Meeting on Paleoseismology, Active Tectonics and Archaeoseismology, Pescina, Italy, 04/2015.

Wessel, P., Smith, W.H.F., Scharroo, R., Luis, J. and Wobbe, F., 2013. Generic Mapping Tools: Improved Version Released, EOS Trans. Am. Geophys. Union, 94(45), 409-410. doi: 10.1002/2013EO450001.

Zumberge, J.F., Heflin, M.B., Jefferson, D.C., Watkins, M.M. and Webb, F.H., 1997. Precise point positioning for the efficient and robust analysis of GPS data from large networks, J. Geophys. Res., 102(B3), 5005-5017. 